

\title{
Impact of Veterinary Students' Preparation and Learning Strategies on Academic Success in a Flipped Swine Medicine Course
}

\author{
Perle Emilie Zhitnitskiy \\ Department of Veterinary Population Medicine, College of Veterinary Medicine, University of Minnesota, Saint Paul, MN, USA
}

Abstract

Background: Flipped teaching techniques have been gaining popularity in veterinary curricula. These methods of teaching are shown to increase students' engagement, promote students' self-directed learning, and can even improve their academic success. One barrier to their implementation, however, is the preparation time required by instructors to be ready to participate in active-learning activities in the classroom. Aims and Objectives: This article describes how $3^{\text {rd }}$-year veterinary students prepare for a flipped classroom and if their learning strategies would influence their academic success. Results: Ninety-five percent $(n=87)$ of the students enjoyed the flipped course and the resources provided by the instructor. Seventy-five percent of students $(n=69)$ used the time blocked-off on their calendar to prepare for this course or to study for another one. The most student-used resources were the instructor-developed e-book and short recapitulative videos ( $98 \%$ and $61 \%$, respectively). Students who emphasized critical thinking and effort regulation as their learning strategies were the most successful on their final examination. Conclusion: Flipping the course without adding to student's workload was a challenge and remained a main barrier to implementation.

Keywords: Flipped classroom, learning strategies, preparation, veterinary education

\section{INTRODUCTION}

Flipped classrooms are designed so that students prepare before class, studying concepts and memorizing key points, to be able to participate in active-learning activities within the classroom. Students are thus expected to attain the lowest levels of Bloom's taxonomy, such as memorizing and understanding, through individual work at home, to be able to apply this new knowledge in class. Faculty members may elect to provide study materials in a large variety of ways but the majority tend to lean toward giving access to diverse types of material to review before class. A survey of veterinary faculty showed that $65 \%$ of them expected their students to review materials before class, either paper based or online, and only $16 \%$ included active learning-type activities to be completed before class. ${ }^{[1]}$

Using a flipped classroom model led to increased engagement and greater satisfaction with learning resources in Australian preveterinary students. ${ }^{[2]}$ In this same study, the flipped classroom model had a positive effect on students' academic performance as demonstrated by an increase in the class

\begin{tabular}{|l|l|}
\hline \multicolumn{2}{|c|}{ Access this article online } \\
\hline Quick Response Code: & Website: \\
\hline & www.ehpjournal.com \\
\hline & \\
\hline
\end{tabular}

median grade on the final examination from $53 \%$ to $63 \%$. These findings were corroborated by two meta-analysis performed on the effect of flipped classrooms on the education of students in health sciences that revealed the same results. ${ }^{[3,4]}$ Veterinary faculty have been adopting flipped classrooms as well, and an international survey has shown that veterinary instructors believed a flipped classroom technique increases active learning in the classroom as well as students' engagement and provides them with opportunities to apply content. ${ }^{[1]}$

In addition, in a flipped course teaching veterinary professional skills, North American students were much more satisfied with the quality of the course $(62 \%$ strongly agreed

Address for correspondence: Dr. Perle Emilie Zhitnitskiy, College of Veterinary Medicine, University of Minnesota, AS/VM 385J, 1988 Fitch Ave, Saint Paul, MN, 55108, USA. E-mail: pboyer@umn.edu

This is an open access journal, and articles are distributed under the terms of the Creative Commons Attribution-NonCommercial-ShareAlike 4.0 License, which allows others to remix, tweak, and build upon the work non-commercially, as long as appropriate credit is given and the new creations are licensed under the identical terms.

For reprints contact: reprints@medknow.com

How to cite this article: Zhitnitskiy PE. Impact of veterinary students' preparation and learning strategies on academic success in a flipped swine medicine course. Educ Health Prof 2020;3:8-15.

Submission: 19.11.2019 Revision: 30.11.2019

Acceptance: 06.12.2019 Web Publication: 12.03 .2020 
or agreed) compared to the traditional delivery (40\% agreed or strongly agreed). In both models, however, the importance of the teaching staff for the motivation of students was highlighted (67\% agreed or strongly agreed) ${ }^{[5]}$

Students' success in the flipped classroom is dependent on how much preparation they have done outside the classroom. If students do not come to class with a "prepared mind," they are less likely to perform well, ${ }^{[2]}$ but getting students to complete reading assignments has been a recurring challenge in higher education. Research has shown that using a quiz to check on students' preparedness at the beginning of class is the strongest motivator and initiator of behavior change in students who were not compliant with reading assignments. ${ }^{[6]}$ More than $80 \%$ of the veterinary students surveyed by Gledhill et al. responded that online quizzes provide a useful opportunity for their self-directed learning. ${ }^{[7]}$ Research also suggests that veterinary instructors believe flipped classroom techniques can encourage students' preparation and self-directed learning in addition to improving students' examination preparation. However, the same instructors also recognize that students' lack of engagement with the material or in class as well as their resistance to this new model of teaching can be strong barriers to the success of the flipped method. ${ }^{[1]}$

If success in the flipped classroom relies on preparation, instructors need to be mindful of the preparation work required and the time needed to complete it. This challenge is exacerbated in professional degrees such as the Doctor of Veterinary Medicine (DVM) program, for which the number of credits students need to take is fixed and the number of concomitant classes is high. As a result, the lack of students' time to complete preparation work has been identified as the biggest barrier to implementing flipped teaching techniques in medical and veterinary courses. ${ }^{[1,8]}$

Little information is available regarding the time spent by health sciences students preparing for flipped courses or how they interact with the provided material. A study of 25 Dutch medical students found that in preclinical and clinical courses, given a variety of material to study from, students primarily chose to use web-based lectures and text readings to prepare for a flipped classroom; formative questions and clinical cases were the next most frequently used resources. Journal articles and textbook chapters were the least favored among students. ${ }^{[9]}$ Another study looked at types of resources preferred by 241 American medical students to prepare for an anatomy laboratory. Three-dimensional anatomy videos of $10 \mathrm{~min}$ each and five to 10 key atlas figures were deemed most useful by the students ahead of a class using abbreviated dissection instructions. ${ }^{[10]}$ These results are consistent with the findings from an international survey that found more than $60 \%$ of veterinary students use social video platforms (such as YouTube and Facebook) for learning more than once a week. As a result, it is predictable that more than $80 \%$ of veterinary students surveyed internationally agreed or strongly agreed that learning from multimedia enhanced their learning. ${ }^{[7]}$
In conclusion, flipped teaching techniques can be successful within health science education provided that instructors are mindful of the time commitment expected of their students to prepare before class and that supporting resources are selected to best prepare students in that expected study time. Sparse information is available in the realm of veterinary education regarding how students prepare for a flipped classroom, what type of resources they favor, the learning strategies they use, and if their learning organization affects their academic success.

The objectives of this study were to determine the following:

- Can a section of a veterinary medicine course be flipped without increasing the workload of the enrolled students?

- How do veterinary students prepare for a flipped course? What type of resources do they use the most?

- Do students' learning strategies influence their academic success?

\section{Methods}

\section{Educational setting and structure of the course}

During the $3^{\text {rd- }}$ year of the DVM curriculum, the students were exposed to the topic of infectious swine disorders through 18 dedicated hours that are part of a required semester-long large animal medicine course. Historically, this content was taught as 18 face-to-face lectures of $50 \mathrm{~min}$ each, delivered by seven different instructors. Assessment of learning objectives was accomplished by a multiple choice final examination designed by several of the instructors. In the fall semester of 2018 , content in this swine course was flipped and organized based on the following model. The number of instructors was reduced to one to ensure consistency in the delivery of the course content. Based on the notes from the previous years, the instructor created an electronic book (ebook) in which each chapter focused on a disease of importance in the swine curriculum. The ebook was interactive and included embedded questions for students to test their knowledge as they progressed through the book. In addition, the instructor recorded a short ( $<4 \mathrm{~min}$ ) video for each disorder in which they summarized and highlighted the major points students should remember before coming to class. Lastly, review articles from scientific journals were provided for students who wished to get more information. Out of the original $18 \mathrm{~h}$ provided for the swine section of the course, nine were allocated to preparation time for students and were blocked out on their schedule to allow them to prepare for the next class if desired. The remaining $9 \mathrm{~h}$ were face-to-face sessions organized as shown in Figure 1.

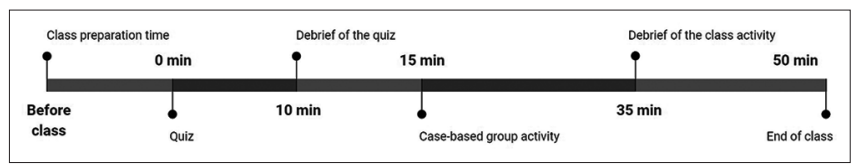

Figure 1: Timeline of a typical face-to-face session in the flipped swine course 
After the nine sessions, students were given 1 week to complete a 2-h online closed-book examination that that covered the swine section of the course; it consisted of multiple choice questions based on the cases covered in class.

\section{Participants}

Course data were collected by the instructor and handled in accordance with the protocol number 00004544 approved by the University of Minnesota IRB committee.

All of the $993^{\text {rd }}$-year veterinary students enrolled in the large animal medicine course were given the option to participate in this study. Students were incentivized to participate by offering them one additional point counting towards their final grade (out of 108) if they chose to participate in the study and answer the postcourse survey. The examination was graded automatically by the learning management system and students were assigned their grades before the results of the survey were analyzed to encourage students' candid participation.

\section{Instrumentalization}

The Motivated Strategies for Learning Questionnaire tool was originally developed to evaluate undergraduate college students learning strategies but has since then been extrapolated to medical students. ${ }^{[9,11]}$ This tool differentiates nine strategies as follows:

- Organization: clustering, outlining, and selecting the main idea in reading passages

- Critical thinking: applying previous knowledge to new situations to solve problems, reach decisions, or make critical evaluations

- Time and study environment: scheduling, planning, and managing one's study time and choosing one's environment to do class work

- $\quad$ Peer learning: collaborating with peers

- Rehearsal: reciting or naming items from a list to be learned

- Effort regulation: controlling effort and attention in the face of distractions and uninteresting tasks

- Metacognitive self-regulation: planning (goal setting and task analysis), monitoring (tracking one's attention as one's read, self-testing, and questioning), and regulating (fine-tuning or continually adjusting one's cognitive activities)

- Help seeking: managing the support of others both peers and instructors

- Elaboration: storing information into long-term memory by building internal connections between items to be learned.

\section{Data collection}

A survey containing 33 questions was posted on the course website for students to answer at the end of the semester [Table 1]. It was divided into three parts: focusing on the students' overall satisfaction with the course, the way students prepared for class, and finally, their learning strategies. Questions regarding the overall satisfaction with the course were created based on standard course evaluation surveys that students are asked to fill out after each course they are attend as part of the DVM program. Questions regarding preparation for the class and learning strategies were designed based on previously published work. ${ }^{[9,11]}$

Several statements related to each of the nine learning strategies were presented to the students and each of them was to be rated on a Likert scale from "I completely disagree" (1) to "I completely agree" (5). A total score for each learning strategy was calculated by adding the students' score on the Likert scale for each of the statements, and the average of the total scores was used when comparing students' learning strategy preferences. Finally, the final examination scores for the swine section were collected for each of the students.

\section{Statistical analysis}

The analysis of the data was completed using SAS 9.4 (SAS, Cary, USA). The distribution of final examination grades was normal; an analysis of variance (ANOVA) was completed to evaluate the effect of reading the ebook, watching the videos, and reading the scientific reviews of the final score. In a similar manner, the effect of using the blocked-off hour to study for the swine session was evaluated. An ANOVA was used to assess the effect of each learning strategy on the final examination score, and if significant, a Fisher's least significant difference test was used to do a pairwise comparison between multiple groups. Finally, a linear regression was done when the plotting of the data suggested that such a correlation might exist.

For all of the analyses, the limit for significance was set at 0.05 .

\section{RESULTS}

Ninety-two of the 99 students chose to respond to the survey, resulting in a $93 \%$ response rate.

\section{Course satisfaction}

Overall satisfaction with the swine section of the course was high: $93 \%(n=86)$ were either satisfied or very satisfied with the course. Satisfaction with the information resources showed that $95 \%(n=87)$ of students either very much enjoyed or enjoyed the resources provided. Finally, 75\% $(n=69)$ of students found the swine course either very valuable or valuable for their careers [Figure 2].

In their open-ended answers regarding what they enjoyed within the course, students emphasized the information resources

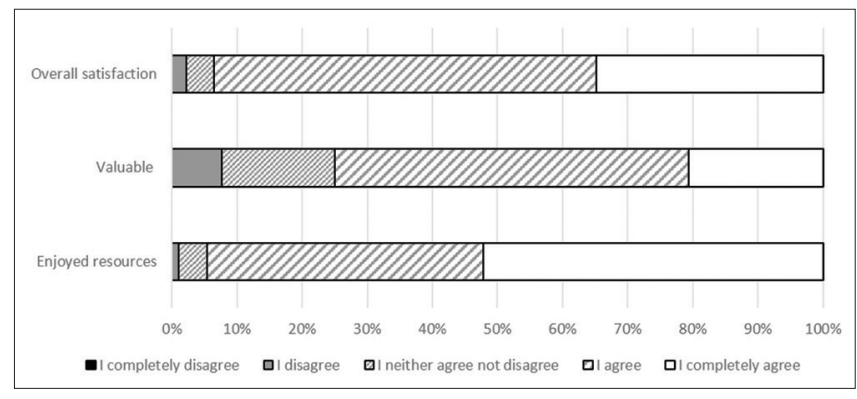

Figure 2: Overall satisfaction of the students with the swine section of the course 


\begin{tabular}{l}
\hline Table 1: Survey items \\
\hline Topic and question type \\
\hline Course satisfaction \\
Likert scale (1-5) \\
Completely agree-completely disagree \\
Open-ended \\
\\
Class preparation \\
Likert scale (1-5) \\
Completely agree-completely disagree
\end{tabular}

Allocated study time

Type of learning: Organization

\author{
Likert scale (1-5) \\ Completely agree-Completely disagree
}

Type of learning: Critical thinking

\author{
Likert scale (1-5) \\ Completely agree-Completely disagree
}

Type of learner: Time management

\author{
Likert scale (1-5) \\ Completely agree-Completely disagree
}

Type of learner: Peer-learning

Likert scale (1-5)

Completely agree-Completely disagree

Type of learner: Rehearsal

\author{
Likert scale (1-5) \\ Completely agree-Completely disagree
}

Type of learner: Effort regulation

\author{
Likert scale (1-5) \\ Completely agree-completely disagree
}

Type of learner: Self-regulation

\author{
Likert scale (1-5) \\ Completely agree-Completely disagree
}

Type of learner: Help seeking

\author{
Likert scale (1-5) \\ Completely agree-completely disagree
}

Type of learner: Elaboration

\author{
Likert scale (1-5) \\ Completely agree-Completely disagree
}

\section{Questions}

I am satisfied with the overall quality of the swine portion of the course

The swine portion is valuable to me as a veterinary student

I enjoyed the resources that were provided to prepare for the in-class sessions

What worked well in the swine section of the course?

What could be improved in the swine section of the course?

I prepared for class by reading the chapters of the e-book

I prepared for class by watching the videos in the e-book

I prepared for this class by reading the optional scientific reviews

Did you use the $1 \mathrm{~h}$ dedicated time slots to prepare for this class? Yes/No

If not, what did you use that time for?

I studied for another class, I worked at a compensated/paid job, I worked at a non-compensated/unpaid job (externships, shadowing...), I ran personal errands, Other (please explain in open-ended response)

Regarding the 1-hour preparation time, which statement do you agree with more? I could prepare for the in-class sessions in 1 hour or less. $/ 1 \mathrm{~h}$ was not enough time for me to prepare for the in-class sessions

When I study the readings for this course, I outline the material to help me organize my thoughts When I study for this course, I go over my class notes and make an outline of important concepts When I study for this course, I go through the readings and my class notes and try to find the most important ideas

I often find myself questioning things I hear or read in this course to decide if I find them convincing When a theory, interpretation, or conclusion is presented in class or in the readings, I try to decide if there is good supporting evidence

I treat the course material as a starting point and try to develop my own ideas about it

I make good use of my study time for this course

I have a regular place set aside for studying

I try to work with other students from this class to complete the course assignments

When studying for this course, I often set aside time to discuss course material with a group of students from the class

When studying for this course, I read my class notes and the course readings over and over again I memorize key words to remind me of important concepts in this class I make lists of important items for this course and memorize the lists

I work hard to do well in this class even if I don't like what we are doing Even when course materials are dull and uninteresting, I manage to keep working until I finish

I ask myself questions to make sure I understand the material I have been studying in this class I try to change the way I study in order to fit the course requirements and the instructor's changing style

I ask the instructor to clarify concepts I don't understand well I try to identify students in this class whom I can ask for help if necessary

I try to relate ideas in this subject to those in other courses whenever possible When I study for this course, I write brief summaries of the main ideas from the readings and my class notes I try to apply ideas from course readings in other class activities such as lecture and discussion 
provided. The ebook $(n=51)$ and the videos $(n=25)$ were often mentioned as their favorite part of the class. Students also appreciated the concise chapters and the short duration of the videos to help them fit better within their busy schedule. The flipped format was seen as another positive aspect: 31 students enjoyed the preclass quizzes, 20 appreciated having to work in groups during class, and 25 liked the case-based exercises.

Challenges highlighted by students included issues with the scheduling of the course, which was at the end of the semester overlapping with "finals week" $(n=58)$. Twenty-one students emphasized that $1 \mathrm{~h}$ in class to finish the exercises and debrief as a large group was too short and that the in-class period should be extended to 1 or $1.5 \mathrm{~h}$.

\section{Student preparation for the course \\ Use of information resources}

Most of the students $(97.5 \%, n=88)$ read the ebook to prepare for the in-class session; a lower proportion $(61 \%, n=56)$ watched the videos. The review articles saw little use, with only $4.3 \%(n=4)$ reading the publications before class [Figure 3].

Statistical analysis showed that there was a significant effect between how much the students used the ebook to prepare for class and their final examination score. Students' examination score were higher at the extremes Likert scores compared to the middle ones [Figure 4a]. A pairwise comparison showed a significant difference $(P=0.046)$ between the group with

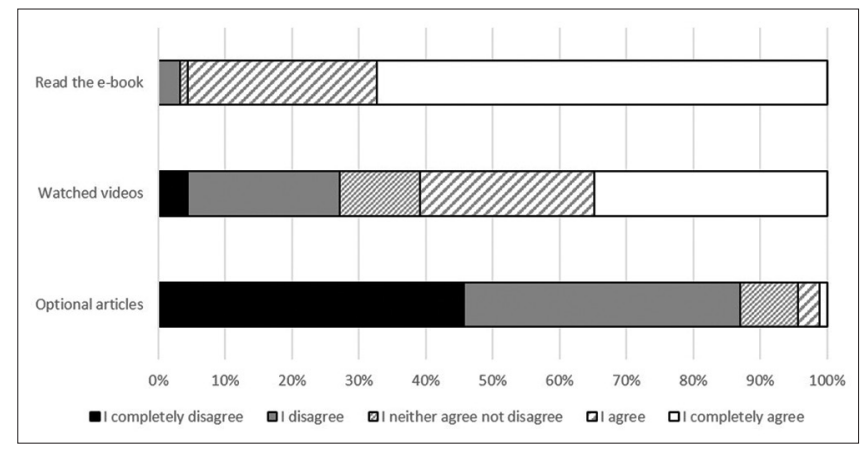

Figure 3: Usage of the various resources by the students to prepare for class a Likert score of 2 ( $n=3$; disagree with the statement " $I$ prepared for class by reading the chapters of the e-book") and the group with a Likert score of $4(n=26$; agree with the statement "I prepared for class by reading the chapters of the e-book"). Between the group with a Likert score of 4 and a Likert score of $5(n=62)$ (strongly agree with the statement "I prepared for class by reading the chapters of the e-book"), there was also a significant difference in final examination score $(P<0.05)$.

Predicted final examination score increased with the students' level of agreement with the statement I prepared for class by watching the videos in the e-book; a positive linear correlation was found between the Likert score of the students regarding this question and their final score $(P=0.014)$ [Figure 4b].

No difference in the final examination score was found based on the students preparing by reading the optional scientific reviews $(P=0.93)$.

\section{Use of allocated time}

Most students used the allocated study time to prepare for the class $(n=59,66 \%), 26 \%(n=23)$ of them studied for another class, and 3\% $(n=3)$ ran personal errands [Figure 5]. Five students reported using the time for something outside these categories. In the open-ended question, all students reported they used the hour for personal time, focusing on their mental health by relaxing or exercising. There was no impact on the final examination score based on what students did during their time allocated to study $(P=0.37)$. In addition, $87 \%(n=80)$ of the students reported that $1 \mathrm{~h}$ was enough time to prepare for the class.

\section{Learning strategies}

Overall, veterinary students in this class clustered around 3.5 for all of the learning strategies, except for "critical thinking and peer-learning" that averaged below 3 and for "effort regulation" which was around 4 [Table 2].

There was no impact of the following learning strategies: organization $(P=0.07)$, time $(P=0.95)$, peer learning $(P=0.43)$, rehearsal $(P=0.72)$, and self-regulation $(P=0.13)$ on the final examination score.

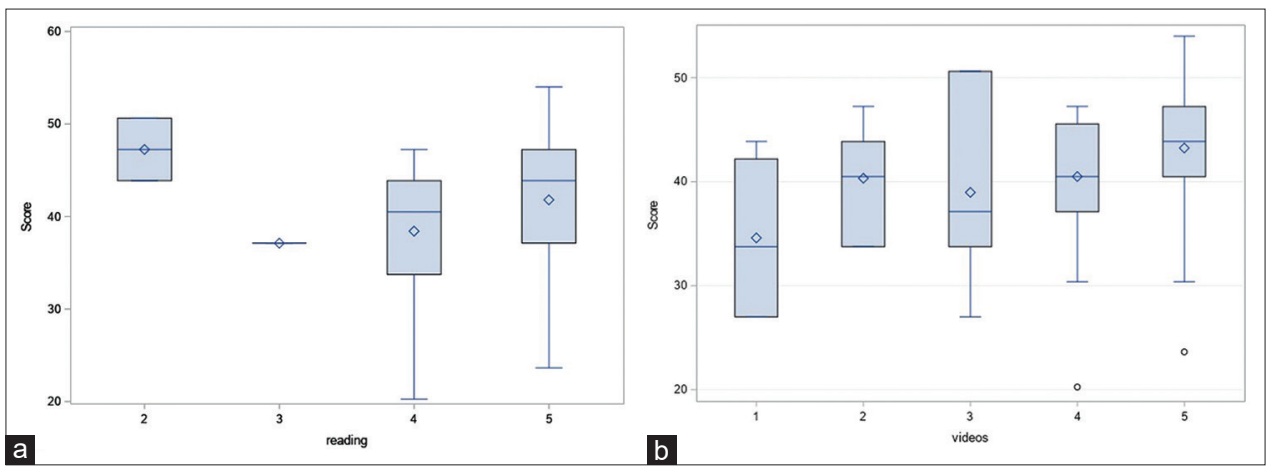

Figure 4: (a) Final examination score distribution based on student's agreement with the statement "I prepared for class by reading the chapters of the e-book." (b) Final examination score distribution based on student's agreement with the statement "I prepared for class by watching the videos in the e-book" 
There was also no significant impact of the self-disclosed critical thinking learning strategy on the final examination score $(P=0.407)$. A bimodal distribution of the data was observed when the data were graphically represented with a box plot however [Figure 6]. If students were separated into two subcategories (those who self-reported a high critical thinking score of $\geq 9$ and those who reported a $<9$ score), the group with the higher critical thinking score showed a significantly higher final examination score $(P=0.024)$.

There was a positive linear correlation between the final examination score and the effort-regulation score reported by students $(P=0.038)$. Indeed, the expected score on the final examination was higher for students who strongly agreed with using an effort-regulation learning strategy.

\section{Discussion}

Students enjoyed the flipped swine course and the information resources provided. This finding is in agreement with previous literature that students in health sciences enjoy this model of teaching. ${ }^{[3,4]}$

While most students took advantage of the e-book chapters and their associated videos to study the material, the impact as a learning strategy was unclear. Students who either used

\begin{tabular}{lc}
\hline Table 2: Learning types score average \\
\hline Learning type & Mean $\mathbf{( 9 5 \% ~ C l )}$ \\
\hline Organization & $3.46(3.25-3.68)$ \\
Critical thinking & $2.91(2.77-3.05)$ \\
Time & $3.63(3.46-3.80)$ \\
Peer learning & $2.96(2.80-3.12)$ \\
Rehearsal & $3.32(3.16-3.47)$ \\
Effort regulation & $3.96(3.84-4.08)$ \\
Self-regulation & $3.54(3.38-3.71)$ \\
Help seeking & $3.52(3.38-3.67)$ \\
Elaboration & $3.61(3.48-3.74)$ \\
\hline
\end{tabular}

\section{CI: Confidence interval}

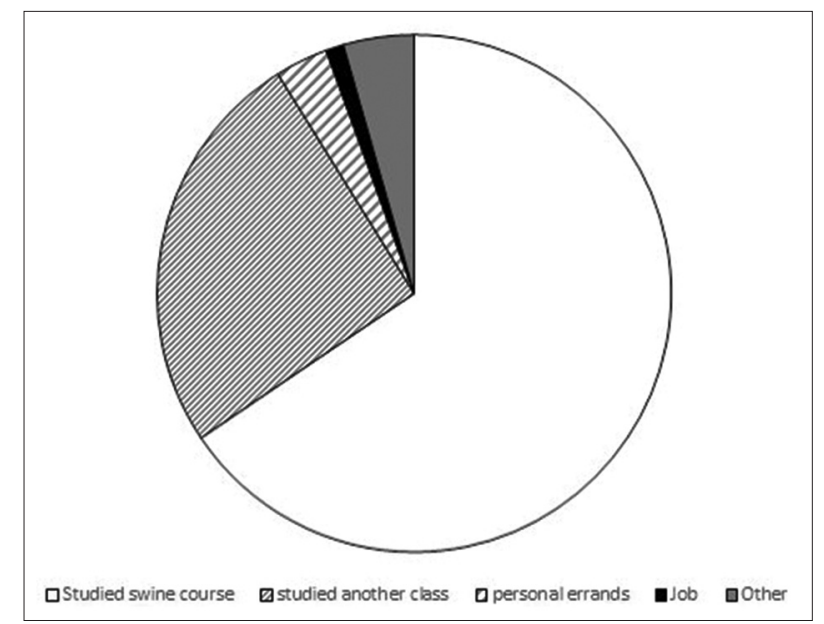

Figure 5: Usage of the 1-h self-study time the ebook chapters a lot or not at all performed better than students reporting that they somewhat used it.

However, a positive correlation between the use of videos to study and student's final examination score was found in this study. This might best be explained by the concise format of the videos, which permitted students to identify the most important points related to each of the diseases and prioritize their learning.

Not many students used the review articles provided. Each review article was more than 10 pages long, and reading them might have felt too time-consuming for the students, especially during a busy time such a "finals' week." This would be consistent with findings from a medical program. ${ }^{[9]}$

Almost a third of students commented in the open-ended questions on the value of quizzes at the beginning of class to make them accountable or to help them learn the material. This finding aligns with previously published literature. ${ }^{[7]}$

When students prepared for the course did not impact their academic success but having dedicated time blocked in their schedule was deeply appreciated, especially by students who used the hours to take care of their mental health. A recent survey has shown that around a third of veterinary students participating had clinical levels of depression or anxiety. ${ }^{[12]}$ Mental health issues have become a priority for veterinary organizations across the world. In 2018, the American Veterinary Medical Association and the Royal College of Veterinary Surgeons released a joint statement committing themselves to "reduce the stigma and prejudice around mental ill-health through education, advocacy and access to services (.....and) to promote a safe and supportive culture in which individuals are able to seek appropriate help and ultimately, flourish."

Promoting students' well-being and mental health needs to be a priority in veterinary schools, and one way to achieve this could be by monitoring students' workload throughout the curriculum and maintaining a constant work requirement

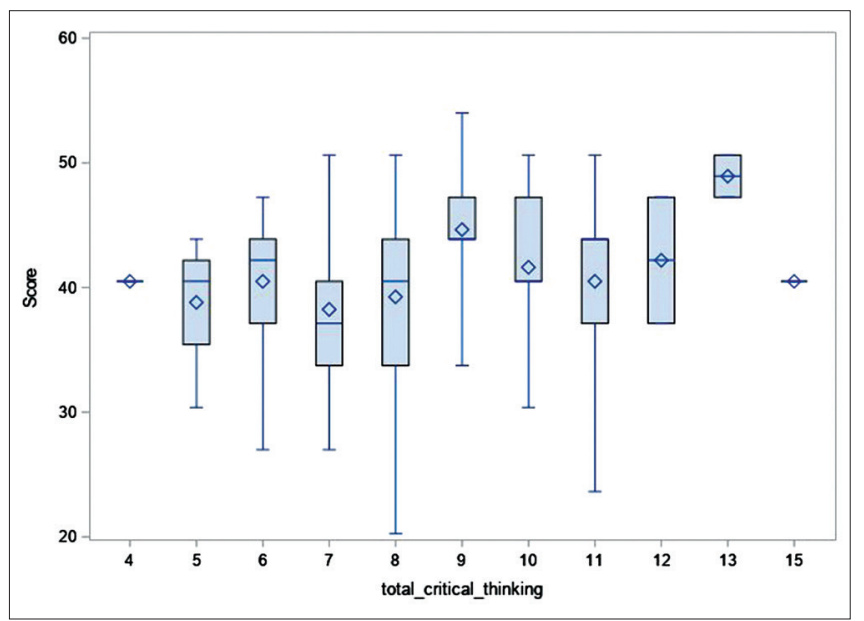

Figure 6: Final examination score distribution based on the total critical-thinking score 
before and after flipping a course. In this study, the limited amount of content was helpful in designing a flipped course that did not add to the workload of students. Fifty-minute face-to-face sessions including a short quiz, feedback on the quiz, group activities, and a debriefing of the activities however gave some students the feeling of being rushed. In the $2^{\text {nd }}$ year, this course was offered using flipped teaching techniques; the instructor extended the face-to-face sessions to $1.5-2 \mathrm{~h}$ depending on the activities needing to be completed. Curriculum committees in veterinary colleges should remain vigilant and consider preparation time carefully, when new courses are proposed to be flipped.

Motivated learning strategies were first identified in the 1990 s, in undergraduate college students and then been extrapolated to medical students to identify what cognitive and metacognitive strategies students put in place to succeed in a course and how they leverage their resources. ${ }^{[9,11]}$ This study revealed that some student learning strategies were more successful than others. Effort regulation strategy can be defined as "controlling effort and attention in the face of distractions and uninteresting tasks". ${ }^{[1]}$ Students who self-reported as using an effort regulation strategy to learn the material performed better than other students, reflecting the propensity to focus on the end task even if they were not particularly interested in the topic. Only a handful of veterinary students in each DVM class report a desire to practice swine medicine on graduation (internal reports, University of Minnesota). As a result, some learners may feel like the topic is less relevant to them and require significant effort to stay focused on and interested in the preclass preparation work.

The other successful learning strategy revealed by this study was critical thinking, defined as applying previous knowledge to new situations. Students who self-reported a high score in critical thinking would tend to perform better on their final examination than other students. This could be explained by a higher level of understanding of the material. Indeed, following Bloom's taxonomy, students only manage to draw connections between ideas after they are able to remember, understand, and analyze the content they are learning. ${ }^{[13]} \mathrm{In}$ this aspect, it does not seem surprising that students who are able to link concepts across classes perform better than their counterparts.

Some limitations of this study include that no control group was included in the study design. There is only one cohort of students taking this course each year, which prevented the creation of concomitant control and treatment groups. Therefore, inferences based on the results need to be drawn carefully. Then, only a small portion of the course was taught using flipped techniques, representing only $18 \mathrm{~h}$ of lectures before being flipped. The limited amount of content was helpful in designing a flipped course that did not add to the workload of students. In addition, motivated learning strategies were self-reported by students on the survey. It is possible that some learners adjusted their answers to those they felt were more appropriate rather than confess their actual approach (e.g. using their reserved time for personal errands) to learning the content.

\section{Conclusion}

Using flipped teaching techniques for a swine medicine course was well accepted by the DVM students. Overall, students enjoyed the sessions and the information resources provided. Flipping the course without increasing students' workload proved to be a challenge. Fifty-minute sessions were too short to include a knowledge check and its feedback, case-based activities, and their debriefing. Veterinary students prepared for class by reading the ebook chapters and watching videos provided by the instructor during the allocated time in their schedule. Students who were able to focus on the content despite distraction or lack of interest as well as students applying knowledge between courses were the most successful on the final examination.

\section{Acknowledgments}

The author would like to thank Dr. Margaret Root Kustritz and Mr. André Nault for their help with the review of this paper. Special thanks to Mr. Joseph Thurston for his help with the development of the ebook chapters.

\section{Financial support and sponsorship}

Financial support for this study was provided from a Teaching Innovation grant from the Center for Educational Innovation at the University of Minnesota and a Partnership for Affordable Content grant from the University of Minnesota libraries.

\section{Conflicts of interest}

There are no conflicts of interest.

\section{References}

1. Matthew SM, Schoenfeld-Tacher RM, Danielson JA, Warman SM. Flipped classroom use in veterinary education: A multinational survey of faculty experiences. J Vet Med Educ 2019;46:97-107.

2. Dooley LM, Frankland S, Boller E, Tudor E. Implementing the flipped classroom in a veterinary pre-clinical science course: Student engagement, performance, and satisfaction. J Vet Med Educ Summ; 45:195-203.

3. Hew KF, Lo CK. Flipped classroom improves student learning in health professions education: A meta-analysis. BMC Med Educ 2018;18:38.

4. Chen F, Lui AM, Martinelli SM. A systematic review of the effectiveness of flipped classrooms in medical education. Med Educ 2017;51:585-97.

5. Moffett J, Mill AC. Evaluation of the flipped classroom approach in a veterinary professional skills course. Adv Med Educ Pract 2014;5:415-25.

6. Sappington J, Kinsey K, Munsayac K. Two studies of reading compliance among college students. Teach Psychol 2002;29:272-4. Available from: http://journals.sagepub.com/doi/10.1207/ S15328023TOP2904_02. [Last accessed on 2018 Sep 20].

7. Gledhill L, Dale VH, Powney S, Gaitskell-Phillips GH, Short NR. An international survey of veterinary students to assess their use of online learning resources. J Vet Med Educ Wint; 44:692-703.

8. Prober CG, Khan S. Medical education reimagined: A call to action. Acad Med 2013;88:1407-10.

9. Bouwmeester RA, de Kleijn RA, ten Cate OT, van Rijen HV, Westerveld HE. How do medical students prepare for flipped classrooms? Med Sci Educ 2016;26:53-60. Available from: http://link.springer. 
com/10.1007/s40670-015-0184-9. [Last accessed on 2018 Aug 02].

10. Fleagle TR, Borcherding NC, Harris J, Hoffmann DS. Application of flipped classroom pedagogy to the human gross anatomy laboratory: Student preferences and learning outcomes. Anat Sci Educ 2018;11:385-96

11. Pintrich P, Smith D, Garcia T, McKeachie W. A Manual for the Use of the Motivated Strategies for Learning Questionnaire (MSLQ); 1991.

12. Karaffa KM, Hancock TS. Mental Health Experiences and Service Use among Veterinary Medical Students. J Vet Med Educ 2019;46:449-58.

13. Bloom BS, Engelhart MD, Furst EJ, Hill WH, Krathwohl D, editors. Taxonomy of Educational Objectives: The Classification of Educational goals. New york: David McKay Company; 1956. 